Case Report

\title{
Primary Renal Carcinoid with Bilateral Multiple Clear Cell Papillary Renal Cell Carcinomas
}

\author{
Daniel A. Anderson ${ }^{1}$ and Maria S. Tretiakova ${ }^{2}$ \\ ${ }^{1}$ Department of Pathology, UWMC Anatomic Pathology, University of Washington, 1959 NE Pacific St., P.O. Box 356100, Seattle, \\ WA 98195-6100, USA \\ ${ }^{2}$ Department of Pathology, University of Washington, 325 Ninth Avenue, P.O. Box 359791, Seattle, WA 98104, USA
}

Correspondence should be addressed to Daniel A. Anderson; danalx@uw.edu

Received 26 March 2017; Accepted 2 May 2017; Published 23 May 2017

Academic Editor: Maria M. Picken

Copyright (c) 2017 Daniel A. Anderson and Maria S. Tretiakova. This is an open access article distributed under the Creative Commons Attribution License, which permits unrestricted use, distribution, and reproduction in any medium, provided the original work is properly cited.

\begin{abstract}
Clear cell papillary renal cell carcinoma (CCPRCC) is a newly recognized entity in the 2016 WHO classification and usually presents as a small, circumscribed, solitary mass of indolent nature. CCPRCCs could seldom occur in conjunction with other synchronous or metachronous kidney tumors and even less frequently as bilateral masses. To our knowledge, multiple bilateral CCPRCCs have never been described with the existence of a synchronous well-differentiated neuroendocrine tumor of the kidney and hence reported here as a unique case. This case report highlights the importance in considering this entity and its unusual presentation in the differential diagnosis as a possible mimicker of Von Hippel-Lindau syndrome.
\end{abstract}

\section{Case Report}

A 55-year-old male with a notable history of diabetes, hypertension, obesity, and chronic kidney disease was found to have bilateral kidney masses while undergoing ultrasound for evaluation of recurrent kidney infections. He was eventually referred to our institution. Computed Tomography (CT) at that time showed a left upper pole $3.2 \mathrm{~cm}$ mass, left lower pole $1.4 \mathrm{~cm}$ mass, a right mid-kidney $6.6 \mathrm{~cm}$ mass, and an upper pole $2.1 \mathrm{~cm}$ mass (Figure 1) which were felt to be stable from a prior CT. A review of a prior biopsy showed small fragments of tissue with CK7 positive, focally CD10 positive clear cells, and mild nuclear atypia which was suspicious for clear cell papillary renal cell carcinoma (CCPRCC).

Resections from the left kidney were performed. The upper pole, lower pole, and the large mid-portion to lower pole masses were removed. All resections showed a histologically typical CCPRCC with a background of simple renal cysts and moderate global glomerular sclerosis, hyperplastic arteriolosclerosis, and lymphoplasmacytic interstitial nephritis.
Several months later, a radical nephrectomy of the right kidney was performed (Figure 1, inset). Pathologic evaluation showed a $6.5 \mathrm{~cm}$ CCPRCC, ISUP (International Society of Urological Pathology) grade 2, of the mid-lower pole which was limited to the kidney (Figure 2). These cells were positive for carbonic anhydrase IX (CAIX) in a cup-like staining pattern, cytokeratin 7 (CK7), and paired box 8 (PAX8) and were negative for neuroendocrine markers synaptophysin and chromogranin. Interestingly, GATA3 also showed diffuse strong positivity of CCPRCC. No abnormalities of Von Hippel-Lindau (VHL) gene, including mutations, methylation abnormalities, and LOH3p, were identified by genetic testing at an outside institution. Just adjacent to the CCPRCC, a microscopically separate $1.5 \mathrm{~cm}$ well-differentiated neuroendocrine tumor was identified focally invading the hilar fat (Figure 3). This was diffusely positive for synaptophysin and chromogranin, variably positive for CK7, and negative for CAIX, PAX8, and GATA3. Of note, no symptoms of carcinoid syndrome were present. In addition to the above histologic findings, simple $0.5-1.5 \mathrm{~cm}$ cortical cysts were identified in a background of focal global glomerulosclerosis 


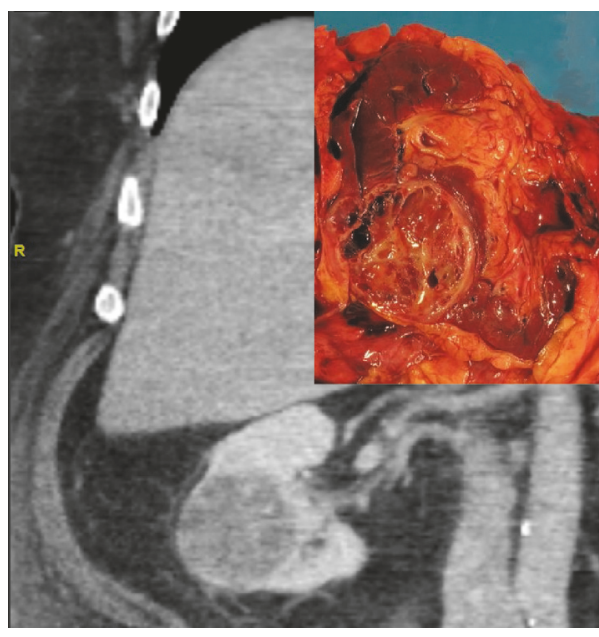

(a)

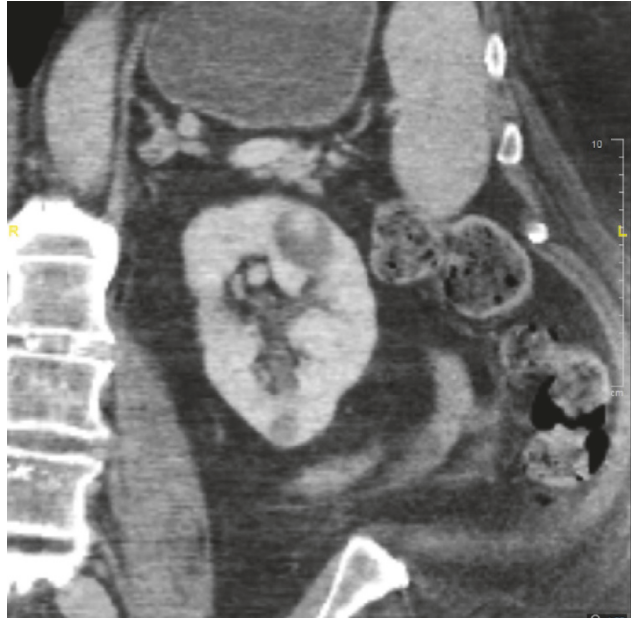

(b)

FIGURE 1: Axial CT images of the (a) right kidney with the largest mid-kidney mass and corresponding gross image [inset] and (b) left kidney with largest upper pole mass.

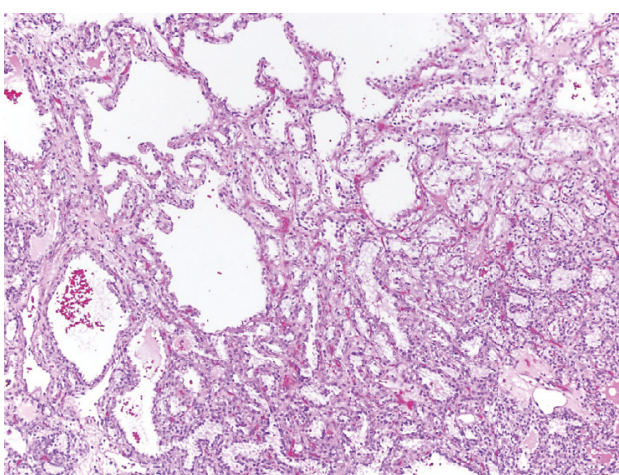

(a)

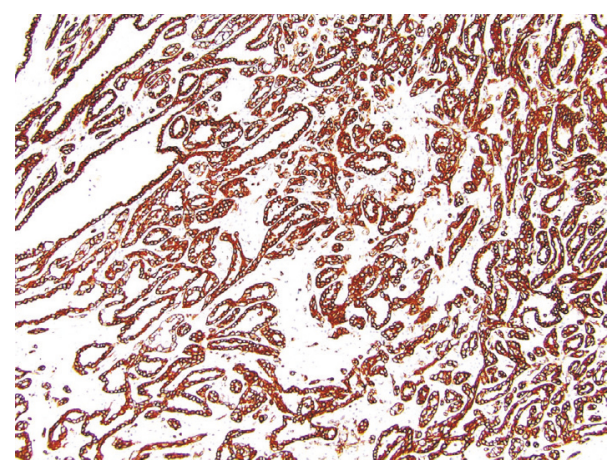

(c)

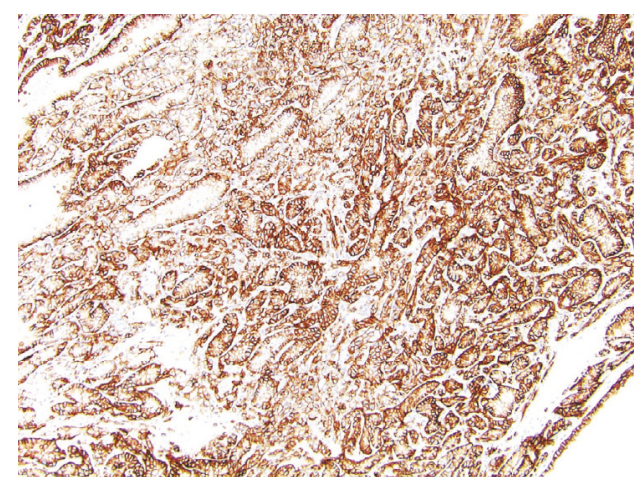

(b)

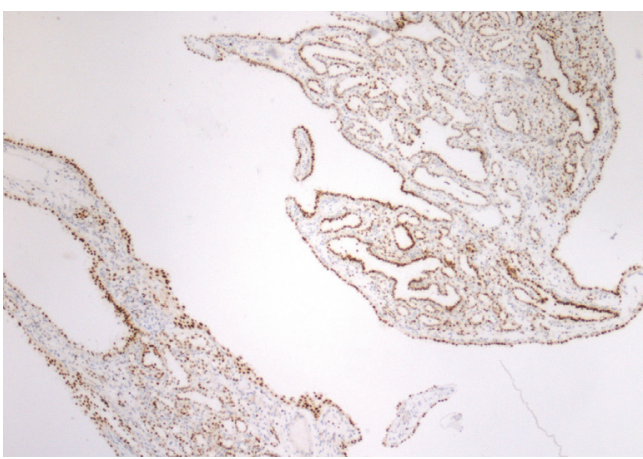

(d)

FIGURE 2: Representative photomicrographs of the CCPRCC component. (a) H\&E section shows tubular, papillary, and cystic components of classic CCPRCC with low-grade clear cells in linear alignment $(\times 20)$ with (b) CAIX showing positivity in a "cup-like" pattern $(\times 20),(c)$ diffuse positivity for CK7 $(\times 10)$, and $(\mathrm{d})$ GATA3 showing diffuse staining $(\times 10)$.

with tubular atrophy, interstitial fibrosis, and moderate to severe arteriosclerosis.
One year after his partial nephrectomy, the patient is doing well with no evidence of recurrence. The patient's 


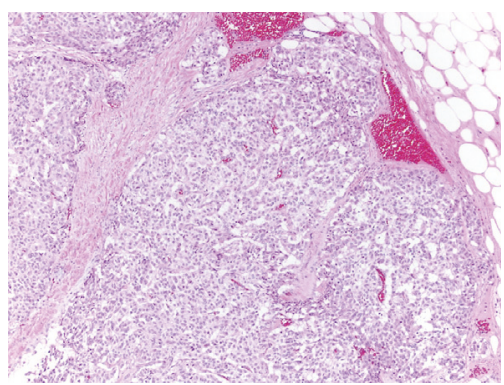

(a)

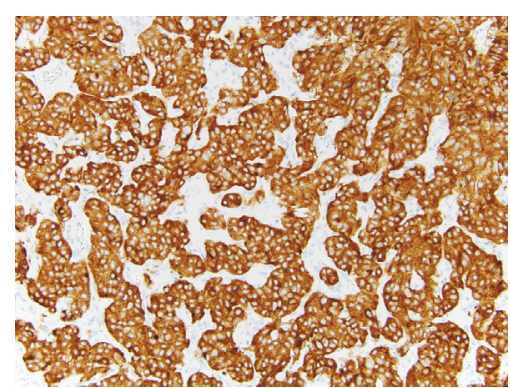

(b)

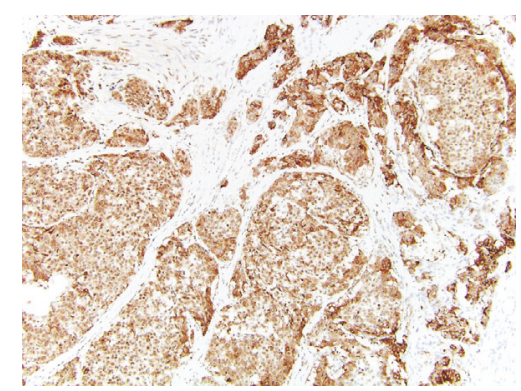

(c)

FIGURE 3: Representative photomicrographs of the well-differentiated neuroendocrine tumor component. (a) H\&E section shows the nested pattern of the well-differentiated neuroendocrine cells $(\times 10)$ with invasion into the hilar fat; (b) synaptophysin $(\times 20)$ and $(c)$ chromogranin $(\times 10)$ are diffusely positive.

chronic kidney disease is stable with creatinine of $1.81 \mathrm{mg} / \mathrm{dL}$ $(0.8 \mathrm{mg} / \mathrm{dL}$ prior to surgery) and does not require dialysis.

\section{Discussion}

CCPRCC was described less than a decade ago [1] as a distinct entity representing $1-4 \%$ of renal epithelial neoplasms $[2,3]$. It was recently recognized in the 2016 WHO classification [4]. CCPRCC is composed of low-grade clear cells (ISUP grade 1 or 2), which contain nuclei polarized away from the basement membrane and a wide range of architectural components including papillary, cystic, acinar nests, ribbons, and solid components. Immunohistochemically, CCPRCC is positive for diffuse CK7 membranous staining, CAIX staining in a "cup-like" pattern, and is negative for TFE3, CD10, and alpha methyl acyl coenzyme A racemase (AMACR) $[5,6]$. The literature has been mixed on the expression of GATA3 in CCPRCCs. Some sources report it as negative [7] while others report CCPRCCs as positive [8]. One study reported that up to one-third of CCPRCCs are positive for GATA3, though staining is reported to be moderate and to be seen in only $10 \%$ of the tumor cells [9]. Analysis of miRNA has shown overexpression of the miR-200 family, a regulator of the epithelial-mesenchymal transition (EMT), which is reflected in CCPRCC's positivity for E-cadherin, vimentin, and $\beta$ catenin and may play a role in CCPRCCs indolent nature [10]. Interestingly, neuroendocrine neoplasms have shown overexpression of the miR-200 family in well-differentiated small intestinal neuroendocrine tumors [11]. In addition, GATA3 expression is found to correlate with elevated Ecadherin levels and plays a role in the reversal of EMT [1214]. The occurrence of the well-differentiated neuroendocrine tumor and the coexisting CCPRCC may be related to miR200 family overexpression.

Though first described in patients with end stage renal disease [15], the majority of CCPRCCs have been found in those with healthy kidneys $[16,17]$. CCPRCC occurs in a wide range of patients' age (18 to 88 years) with a mean age of 70 . Tumors can range from 0.3 to $7.5 \mathrm{~cm}$ with a mean of $2 \mathrm{~cm}$ and a majority being pTla. Multifocal tumors have been described including multiple ipsilateral foci, bilateral foci, and separate synchronous tumors including clear cell renal cell carcinoma, multilocular cystic renal cell carcinoma, oncocytoma, papillary adenomas, papillary renal cell carcinoma, and acquired cystic kidney disease associated renal cell carcinoma [1821]. Though data are limited, current evidence supports the conclusion that CCPRCC have an excellent prognosis and indolent course. There are no convincing reports of recurrences, metastases, or sarcomatoid transformation after surgical excision. Likewise, multifocality and bilaterality do not appear to impart a worse prognosis [2, 22].

Awareness of this newly described combination of CCPRCC and neuroendocrine tumors is critical to consider in the differential diagnosis of VHL syndrome. VHL syndrome can present with multiple clear cell renal cell carcinomas which can mimic CCPRCC morphologically and grossly. However, these tumors differ in their molecular and immunohistochemical profiles [23]. In addition, VHL disease may present with endocrine manifestations including pheochromocytomas, extra-adrenal paragangliomas, and pancreatic neuroendocrine tumors [24]. Though VHL syndrome was a consideration with the constellation of findings described in this case, this was effectively ruled out through immunohistochemistry and genetic testing. Scant evidence suggests that CCPRCC harbors VHL mutations and the classification of such CCPRCC cases with VHL mutations is questionable [10, 25-27].

Primary renal carcinoid tumors are extremely rare. Peak incidence is the fifth and sixth decades of life with a slight female predominance. Renal carcinoids have been associated with horseshoe kidneys and polycystic kidney disease and have been described arising from teratomas, including one case report of a reported adenocarcinoma and a carcinoid arising within a teratoma in a horseshoe kidney $[28,29]$. The neoplasm commonly shows trabecular, pseudoglandular, solid patterns and immunophenotypically expresses neuroendocrine markers [30]. Most carcinoids have an indolent course despite their frequent presentation with regional metastasis to the lymph nodes and documented distant metastases to liver, lungs, and bones [31, 32]. Carcinoids have been associated with loss of heterozygosity of the 3 p12-3p21 region and higher rates of metastases have been reported with tumors greater than $4 \mathrm{~cm}$ and with higher mitoses [33]. In our case, a paraganglioma of the kidney was 
initially entertained. However, morphological assessment as well as lack of GATA3, cytokeratin, and S100 staining of sustentacular cells effectively ruled this out.

CCPRCC has never before been reported to coexist with a primary renal carcinoid tumor much less with bilateral multiple CCPRCCs. Though CCPRCCs have an indolent course, multifocality and synchronous tumors of various types, including well-differentiated neuroendocrine tumors, as described here, must be considered in the prognosis and raise the concern of possible syndromic associations. Further studies are needed to better understand these neoplasms, their interaction, and their underlying mechanisms.

\section{Conclusion}

This is an unprecedented case of a primary renal carcinoid with simultaneous multifocal bilateral CCPRCCs. The presence of concurrent multiple tumors, besides their negative impact on residual kidney function, should be considered in the diagnosis in the otherwise indolent prognosis of CCPRCC. This case report highlights the importance in considering this entity and its unusual presentation in the differential diagnosis as a possible mimicker of Von HippelLindau syndrome.

\section{Conflicts of Interest}

The authors declare that there are no conflicts of interest regarding the publication of this paper.

\section{References}

[1] S. Gobbo, J. N. Eble, D. J. Grignon et al., "Clear cell papillary renal cell carcinoma: a distinct histopathologic and molecular genetic entity," American Journal of Surgical Pathology, vol. 32, no. 8, pp. 1239-1245, 2008.

[2] M. L. Diolombi, L. Cheng, P. Argani, and J. I. Epstein, "Do clear cell papillary renal cell carcinomas have malignant potential?" American Journal of Surgical Pathology, vol. 39, no. 12, pp. 16211634, 2015.

[3] N. Kuroda, C. Ohe, F. Kawakami et al., "Clear cell papillary renal cell carcinoma: a review," International Journal of Clinical and Experimental Pathology, vol. 7, no. 11, pp. 7312-7318, 2014.

[4] H. Moch, P. A. Humphrey, T. M. Ulbright, and V. E. Reuter, WHO Classification of Tumours of the Urinary System and Male Genital Organs, International Agency for Research on Cancer, Lyon, France, 4th edition.

[5] H. Ross, G. Martignoni, and P. Argani, "Renal cell carcinoma with clear cell and papillary features," Archives of Pathology and Laboratory Medicine, vol. 136, no. 4, pp. 391-399, 2012.

[6] H. Aydin, L. Chen, L. Cheng et al., "Clear cell tubulopapillary renal cell carcinoma: a study of 36 distinctive low-grade epithelial tumors of the kidney," American Journal of Surgical Pathology, vol. 34, no. 11, pp. 1608-1621, 2010.

[7] M. R. Raspollini, F. Castiglione, L. Cheng, R. Montironi, and A. Lopez-Beltran, "Genetic mutations in accordance with a low malignant potential tumour are not demonstrated in clear cell papillary renal cell carcinoma," Journal of Clinical Pathology, vol. 69, no. 6, pp. 547-550, 2016.
[8] E. Munari, D. Segala, S. Gobbo et al., "GATA3 expression in clear cell papillary renal cell carcinoma and renal cell carcinoma with prominent leiomyomatous proliferation is a further evidence of the relationship between these two entities," Modern Pathology, vol. 27 supplement, article 250A, 2014.

[9] K.-F. Deml, H.-U. Schildhaus, E. Compérat et al., "Clear cell papillary renal cell carcinoma and renal angiomyoadenomatous tumor: two variants of a morphologic, immunohistochemical, and genetic distinct entity of renal cell carcinoma," American Journal of Surgical Pathology, vol. 39, no. 7, pp. 889-901, 2015.

[10] C. H. Lawrie, E. Larrea, G. Larrinaga et al., "Targeted nextgeneration sequencing and non-coding RNA expression analysis of clear cell papillary renal cell carcinoma suggests distinct pathological mechanisms from other renal tumour subtypes," Journal of Pathology, vol. 232, no. 1, pp. 32-42, 2014.

[11] S.-C. Li, A. Essaghir, C. Martijn et al., "Global microRNA profiling of well-differentiated small intestinal neuroendocrine tumors," Modern Pathology, vol. 26, no. 5, pp. 685-696, 2013.

[12] W. Yan, Q. J. Cao, R. B. Arenas, B. Bentley, and R. Shao, "GATA3 inhibits breast cancer metastasis through the reversal of epithelial-mesenchymal transition," Journal of Biological Chemistry, vol. 285, no. 18, pp. 14042-14051, 2010.

[13] P. Shahi, C. Y. Wang, D. A. Lawson et al., "ZNF503/Zpo2 drives aggressive breast cancer progression by down-regulation of GATA3 expression," Proceedings of the National Academy of Sciences of the United States of America, vol. 114, no. 12, pp. 31693174, 2017.

[14] J. Chou, J. H. Lin, A. Brenot, J.-W. Kim, S. Provot, and Z. Werb, "GATA3 suppresses metastasis and modulates the tumour microenvironment by regulating microRNA-29b expression," Nature Cell Biology, vol. 15, no. 2, pp. 201-213, 2013.

[15] S. K. Tickoo, M. N. DePeralta-Venturina, L. R. Harik et al., "Spectrum of epithelial neoplasms in end-stage renal disease: an experience from 66 tumor-bearing kidneys with emphasis on histologic patterns distinct from those in sporadic adult renal neoplasia," American Journal of Surgical Pathology, vol. 30, no. 2, pp. 141-153, 2006.

[16] M. Aron, E. Chang, L. Herrera et al., "Clear cell-papillary renal cell carcinoma of the kidney not associated with end-stage renal disease: Clinicopathologic correlation with expanded immunophenotypic and molecular characterization of a large cohort with emphasis on relationship with renal angiomyoadenomatous tumor," American Journal of Surgical Pathology, vol. 39, no. 7, pp. 873-888, 2015.

[17] LP. Herrera, M. Hirsch, E. Comperat et al., "Clear cell-papillary renal cell carcinoma (CP-RCC) not associated with end stage renal disease: clinicopathologic analysis of 50 tumors confirming a novel subtype of renal cell carcinoma (RCC) occurring in a sporadic setting," Modern Pathology, vol. 24 Supplement, article 197A, 2011.

[18] S. R. Williamson, J. N. Eble, L. Cheng, and D. J. Grignon, "Clear cell papillary renal cell carcinoma: Differential diagnosis and extended immunohistochemical profile," Modern Pathology, vol. 26, no. 5, pp. 697-708, 2013.

[19] B. A. Alexiev and C. B. Drachenberg, "Clear cell papillary renal cell carcinoma: Incidence, morphological features, immunohistochemical profile, and biologic behavior: A single institution study," Pathology Research and Practice, vol. 210, no. 4, pp. 234241, 2014.

[20] H. Zhou, S. Zheng, L. D. Truong, J. Y. Ro, A. G. Ayala, and S. S. Shen, "Clear cell papillary renal cell carcinoma is the fourth most common histologic type of renal cell carcinoma in 290 
consecutive nephrectomies for renal cell carcinoma," Human Pathology, vol. 45, no. 1, pp. 59-64, 2014.

[21] T. Shao, P. Yousef, I. Shipilova, R. Saleeb, J. Y. Lee, and A. Krizova, "Clear cell papillary renal cell carcinoma as part of histologically discordant multifocal renal cell carcinoma: A case report and review of literature," Pathology Research and Practice, vol. 212, no. 3, pp. 229-233, 2016.

[22] J. Adam, J. Couturier, V. Molinié, A. Vieillefond, and M. Sibony, "Clear-cell papillary renal cell carcinoma: 24 cases of a distinct low-grade renal tumour and a comparative genomic hybridization array study of seven cases," Histopathology, vol. 58, no. 7, pp. 1064-1071, 2011.

[23] S. R. Williamson, S. Zhang, J. N. Eble et al., "Clear cell papillary renal cell carcinoma-like tumors in patients with von hippellindau disease are unrelated to sporadic clear cell papillary renal cell carcinoma," American Journal of Surgical Pathology, vol. 37, no. 8, pp. 1131-1139, 2013.

[24] C. Cassol and O. Mete, "Endocrine manifestations of von Hippel-Lindau disease," Archives of Pathology and Laboratory Medicine, vol. 139, no. 2, pp. 263-268, 2015.

[25] E. R. Maher, H. P. H. Neumann, and S. Richard, "Von Hippel-Lindau disease: a clinical and scientific review," European Journal of Human Genetics, vol. 19, no. 6, pp. 617-623, 2011.

[26] S. R. Williamson, N. S. Gupta, J. N. Eble et al., "Clear cell renal cell carcinoma with borderline features of clear cell papillary renal cell carcinoma: combined morphologic, immunohistochemical, and cytogenetic analysis," American Journal of Surgical Pathology, vol. 39, no. 11, pp. 1502-1510, 2015.

[27] H. P. Dhakal, J. K. McKenney, L. Y. Khor, J. P. Reynolds, C. Magi-Galluzzi, and C. G. Przybycin, "Renal neoplasms with overlapping features of clear cell renal cell carcinoma and clear cell papillary renal cell carcinoma: a clinicopathologic study of 37 cases from a single institution," American Journal of Surgical Pathology, vol. 40, no. 2, pp. 141-154, 2016.

[28] A. O. Omiyale and A. K.-G. Venyo, "Primary carcinoid tumour of the kidney: a review of the literature," Advances in Urology, vol. 2013, article 579396, 11 pages, 2013.

[29] H. B. Armah, A. V. Parwani, and A. M. Perepletchikov, "Synchronous primary carcinoid tumor and primary adenocarcinoma arising within mature cystic teratoma of horseshoe kidney: A unique case report and review of the literature," Diagnostic Pathology, vol. 4, article 17, 2009.

[30] P. P. Aung, K. Killian, C. O. Poropatich, W. M. Linehan, and M. J. Merino, "Primary neuroendocrine tumors of the kidney: Morphological and molecular alterations of an uncommon malignancy," Human Pathology, vol. 44, no. 5, pp. 873-880, 2013.

[31] D. E. Hansel, J. I. Epstein, E. Berbescu, S. W. Fine, R. H. Young, and J. C. Cheville, "Renal carcinoid tumor: a clinicopathologic study of 21 cases," The American Journal of Surgical Pathology, vol. 31, no. 10, pp. 1539-1544, 2007.

[32] B. T. Shurtleff, O. Shvarts, and J. Rajfer, "Carcinoid tumor of the kidney: case report and review of the literature," Reviews in Urology, vol. 7, no. 4, pp. 229-233, 2005.

[33] F. R. Romero, S. Rais-bahrami, S. Permpongkosol, S. W. Fine, S. Kohanim, and T. W. Jarrett, "Primary carcinoid tumors of the kidney," The Journal of Urology, vol. 176, no. 6, part 1, pp. 23592366, 2006. 


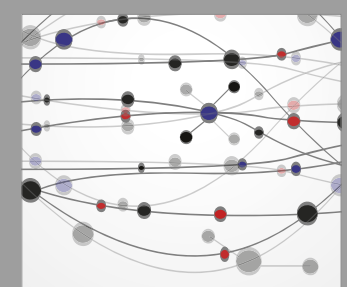

The Scientific World Journal
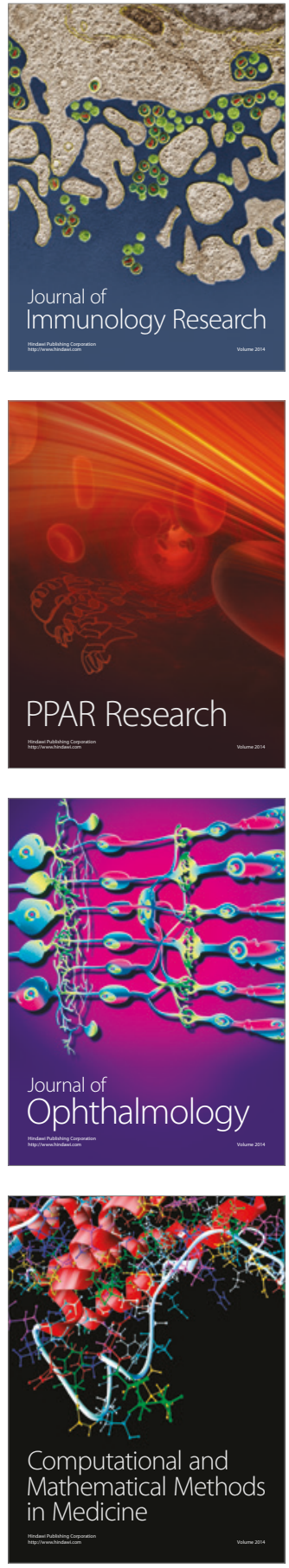

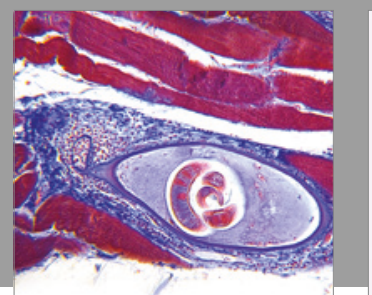

Gastroenterology Research and Practice
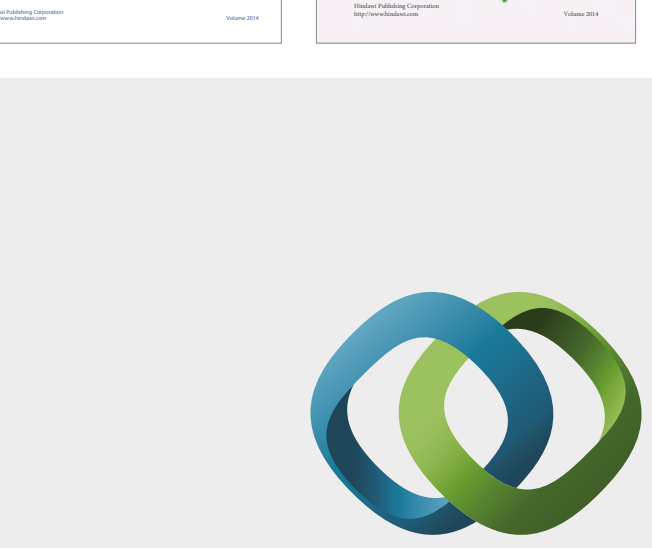

\section{Hindawi}

Submit your manuscripts at

https://www.hindawi.com
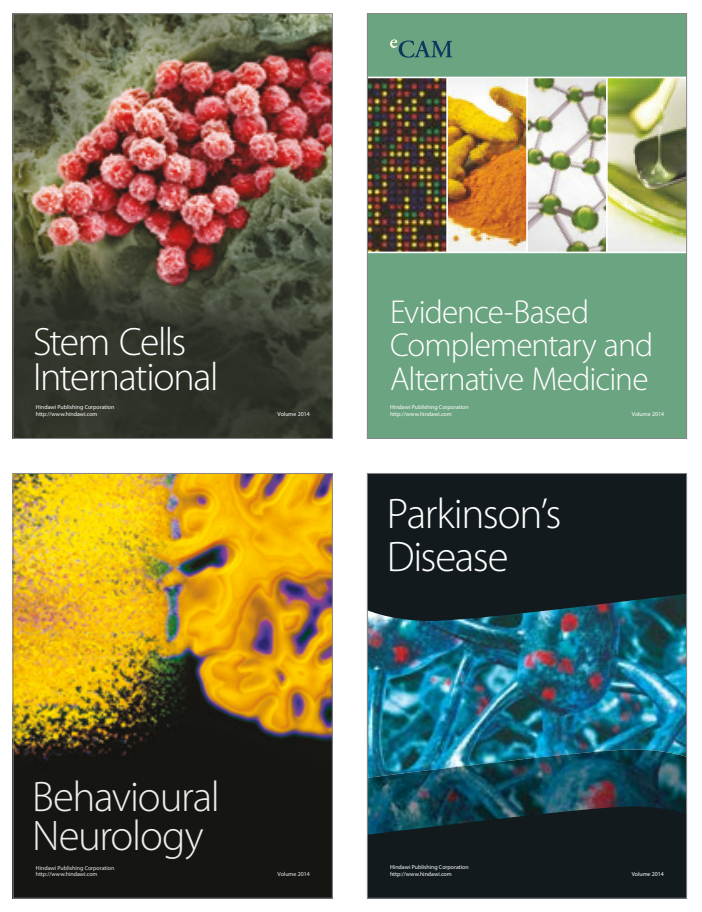
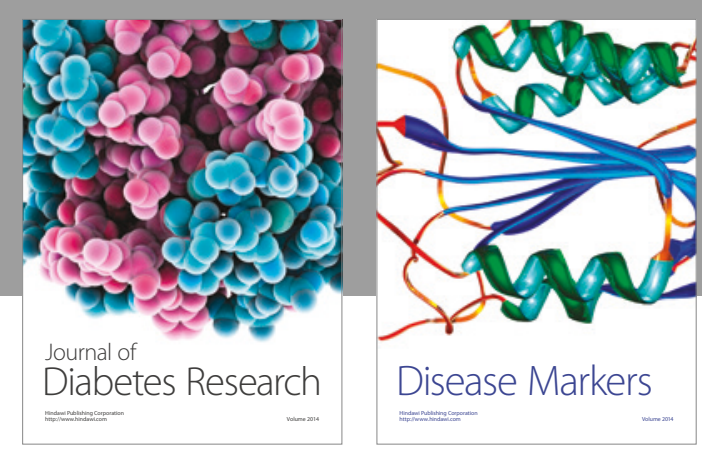

Disease Markers
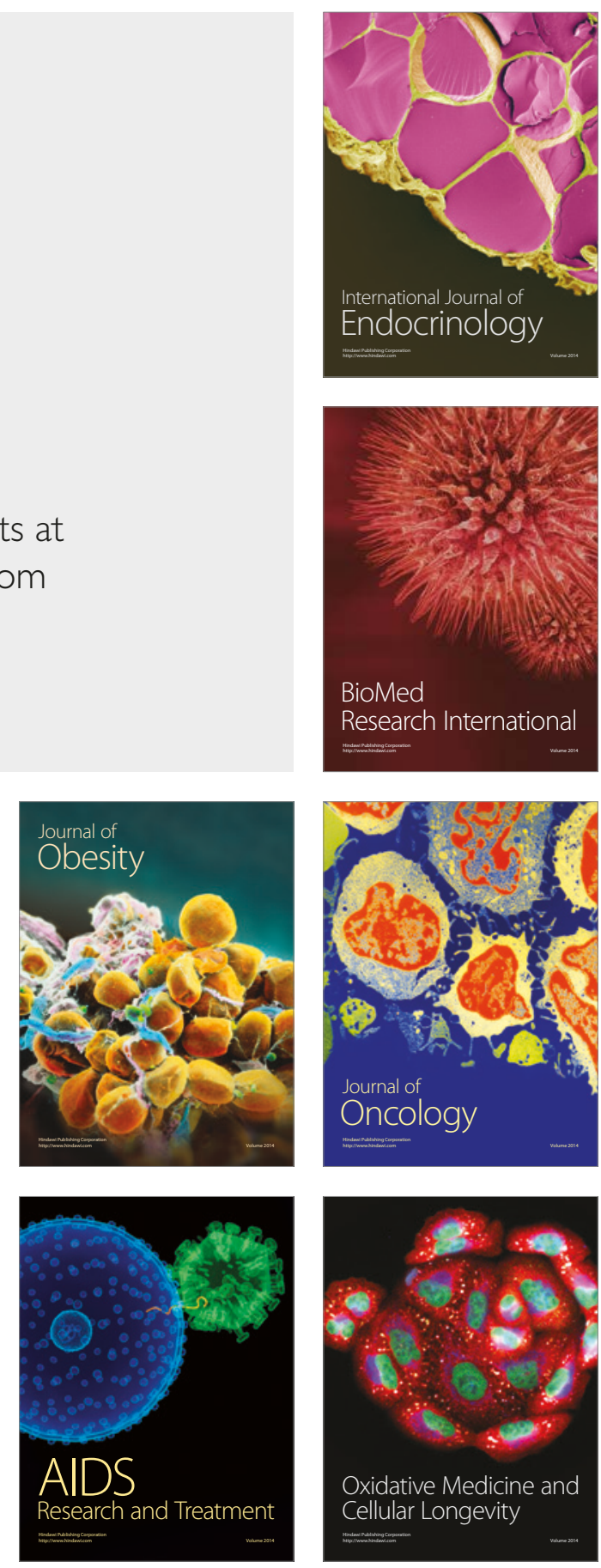